\title{
LENGUAJE TEATRAL Y SICOLOGÍA
}

Muchos son los campos en que, de un tiempo a esta parte, incide la colaboración de lingüistas y sicólogos: el problema del sentido de la frase, la estructura sicológico-gramatical, las relaciones entre pensamiento y lenguaje, las categorías de tiempo y aspecto verbales, el problema de las palabras abstractas y las concretas, el extraordinario fenómeno de la expresividad, la patología del lenguaje. Sin esta vinculación, no sería grande la victoria obtenida por unos y por otros en áreas donde muchos de los temas anotados constituyeron durante largos años enigma y atracción. Hoy es necesario ahondar más en esa colaboración para investigar en otros campos: los ritmos de acentuación en los afásicos, las áreas semánticas en los tests de asociación verbal son, para citar algunos, campos no visitados todavía por la investigación mancomunada ${ }^{1}$.

Clara es para todos la relación estrecha entre la intención del hablante y la modulación del tono impreso a la frase. La entonación es, por eso, reveladora de sentido en la lengua oral; a través de ella el oyente interpreta (y la palabra es significativa) el mundo afectivo del hablante, el trasfondo sentimental de un contexto, guiado por el indicio de la entonación. No es secreto. A veces, a la combinación de cadencias y anticadencias se suma otro elemento, el tempo rítmico, garantizado por el equilibrio acentual. El ritmo de la expresión oral es síntoma del mundo interior. Cualquiera puede comprobarlo en las distintas situaciones a que nos convoca la vida cotidiana. El teatro proporciona, de otro lado, un eficaz observatorio.

Estos fenómenos se tornan difíciles de manifestar en el campo de la lengua escrita. La lengua escrita no ofrece esa labilidad de la lengua coloquial. ¿No tiene el hablante más recurso que la organización sintáctica para traducir por escrito su emoción? ¿Y las insinuaciones confiadas a la voz, a qué quedan reducidas, cómo se logran transmitir por escrito? Un ojo experto sabrá descubrirlas a través de la situación en que se inserta el circuito hablante-oyente, y podrá rastrearlas en la estructura de la frase. Pero es tarea espe-

1 Escojo estos dos ejemplos, para referirme únicamente a problemas de mi especial preocupación. En el de los afásicos vengo realizando observaciones desde hace años, y he contado con los auxilios de la Clínica San Isidro y del Servicio de Neurología del Hospital Obrero de Lima. 
cializada, supone interpretación (= estudio, crítica), y no la realiza ahora el oyente común. Por lo menos no la realiza en el ámbito cerrado de la estricta lengua escrita. Pero sí puede descubrirla en el lenguaje del teatro, subespecie de la lengua oral. El lenguaje "teatral" nos proporciona materiales provechosos. Pero es necesario adelantar una afirmación imprescindible, de capital importancia. El lenguaje teatral implica para el hablante una urgente y complejísima tarea lingüistica: debe realizar (= organizar) una estructura dinámica de lenguaje espontáneo, que es el típico de la conversación, el reclamado por el escenario. Es decir, debe imponerse realizar voluntariamente un lenguaje automático. No se ha dado aún suficiente importancia a este problema en los tratados de lingüística. Se trata de un fenómeno de estilo, que afecta al campo síquico, y del que no hay aún conciencia clara. Bally destacó en su oportunidad la existencia de un lenguaje espontáneo, impuesto por la situación y privado de participación voluntaria del hablante, frente a un lenguaje voluntario, realizado de acuerdo con procedimientos especiales a que el hablante recurre. El lenguaje manejado por un autor teatral representa un vivo testimonio de esa complejidad: estamos ante un "procedimiento" destinado a manifestar (= poner de manifiesto) un lenguaje impuesto por la situación (= la escena). Y no solamente esto; se trata de ponerlo de manifiesto para que sea inte r pretado. El hablante debe actualizar en palabras un proceso vivido en el espíritu, y convertir dicho proceso en "un sistema articulatorio, mot[or], acústico, dispuesto a servir y ser utilizado por cada sujeto" (GEMELl, Introd. a la psicología, p. 32).

\section{Gesto y Lenguaje}

La complejidad del lenguaje teatral no se reduce ciertamente a lo apuntado. Se enlaza con otro fenómeno, al que en más de una ocasión ha dedicado la sicología sus preferencias: el del gesto. El gesto (la mímica) resulta una especial manera de hacer realidad sicológica el sistema lingüístico. Realizamos con gestos el circuito del habla, y a veces descubrimos fragmentaciones lingüísticas con el exclusivo testimonio del gesto, según lo ha probado la geografía lingüística ${ }^{2}$.

Conviene precisar una observación sobre el "acto lingüístico", a fin de entender con claridad el fenómeno. El acto lingüístico nos coloca ciertamente ante un fragmento de la vida síquica. La palabra

2 Gerhard Rohrfs recordaba en el Coloquio Internacional de Bucarest (1959) que, a diferencia del movimiento de negación expresado con la cabeza en Europa Central y Occidental, "en toda la Italia meridional el gesto de la negación se expresa lanzando la cabeza hacia atrás en sentido vertical”, como en Grecia, Albania, Macedonia. 
no tiene acá alcances arqueológicos; no se trata de un "retazo" de la vida síquica. Hablamos de un fragmento no aislado, sino ligado a otras funciones. Supone una actividad total del organismo y de todos los aspectos de la vida síquica. Es importante hacerse cargo de esta verdad: el acto lingüístico implica una vida síquica en actitud lingüistica. La expresión (o sea, el procedimiento sintáctico a que recurrimos) es sólo la manifestación exterior de esa actividad inter$\mathrm{na}^{3}$. Por cierto, hoy sabemos que el lenguaje no se reduce al fenómeno de la expresión; sabemos que éste se halla encerrado dentro del circuito del habla, y de ello toma buena conciencia el traductort. Estas consideraciones deben ser tenidas muy presentes al estudiar el gesto como instrumento de la organización expresiva, dentro de un sistema.

Quintiliano intuyó los alcances de esta expresividad, y le dedicó curiosas observaciones (Inst., XI, 3). El gesto era más signif i c a tivo que los ademanes; si repetimos acá sus palabras, nos alcanzará la convicción de estar ante fenómenos típicamente vinculados con la expresividad (= estilísticos), reveladores de la intención del hablante: "Con él nos mostramos suplicantes, con él amenazamos, con él halagamos; el gesto nos hace tristes, alegres, soberbios y humildes. . .; por él odiamos y entendemos muchísimas cosas. Sirve muchas veces más que todas las palabras". El gesto aparece, como se ve, encarado como el síntoma de los estados de ánimo, revelador de la vida afectiva. Es un elemento de comunicación, un elemento lingüístico. No interesa tanto que estas palabras vengan dichas a propósito de los oradores, cuanto que muestran a Quintiliano consciente de tratar un problema más vasto ${ }^{5}$, según lo prueban los minuciosos detalles con que quiere abordar la expresividad de los ojos, las mejillas, los párpados, etc. Interesa que nos demoremos en al-

${ }^{3}$ La lengua "no se actualiza en la palabra sino cuando, después de haber sido vivida en el espíritu de cada uno de nosotros, se concreta en un sistema articulatorio, mot[or], acústico, dispuesto a servir y ser utilizado por cada sujeto: por lo tanto, una lengua existe en cuanto haya un lenguaje interior; y existe en nosotros no ya como en los vocabularios o en las gramáticas, como si nosotros sacáramos de nuestro interior en el momento oportuno el vocablo para aplicar a la cosa existente fuera de nosotros, y por nosotros concebida, sino como expresión viva de toda una organización psíquica" (Gemell, p. 342). Alguna vinculación tiene este asunto con la Innersprachform, pero no coincide evidentemente con lo que conocemos los lingüistas por actitud idiomática; parece ser, eso sí, la antesala de la base articularia reconocida por Amado Alonso en fonética (RFH, 3, 1941, p. 212 ).

4 Lo que nos coloca ante el sentido de un texto es la confluencia de estas dos corrientes. El traductor sabe que no puede satisfacer su cometido con sólo comprender; debe interpretar. La interpretación es, en el circuito del habla, el extremo contrario a la organización de la expresión.

5 Por eso aludirá en seguida al beneficio de los gestos en el teatro, como factores de expresividad. 
gImas de sus apreciaciones, para medir su actualidad ${ }^{6}$. Se diría que Quintiliano está haciendo sicología al poner de relieve "la influencia que ejerce la actividad afectiva sobre el lenguaje" (= el gesto); no tenemos inconveniente en admitirlo hoy: el dinamismo, la vitalidad de una lengua se hacen presentes a través de esos signos de afectividad. Quintiliano parecía saber que una lengua no es una mera sucesión de sonidos, e intuía -como buen retórico- que era además un conjunto de matices, de insinuaciones, y que estaba dirigida con más fuerza a la esfera imaginativa del oyente que a su estrecha esfera auditiva. Concebir hoy una lengua "como una cadena de sonidos invariables es no haber comprendido su significado" (GEMELLI, p. 35o).

El "Lenguaje" DE LOS ojos

A los ojos confía Quintiliano la mayor responsabilidad expresiva; les corresponde "el máximo efecto" porque a través de ellos "se expresa el alma" con mayor eficacia. Ya estén en reposo, ya en movimiento, sabe que los ojos se revisten de significación. Fue Quintiliano más prudente que algunos exaltados poetas en atribuir cualidades anímicas especiales a los distintos colores del ojo; se limitó a consignar que los ojos inundados de claridad denotaban alegría, y que una nube solía empañar los ojos penetrados de tristeza. Por cierto, cuando Quintiliano habla de los ojos, nos obliga a pensar en el globo ocular. Esta tesis de los valores expresivos del ojo fue combatida empeñosamente en el siglo xrx, y a H. Magnus (Die Sprache der Augen) debemos testimonios elocuentes de esa posición. Sino que nadie habla, en rigor, del valor "aislado" que puede alcanzar el globo ocular; el ojo integra un sistema expresivo, el de la cara ${ }^{7}$. El movimiento de los ojos, por el que la ciencia iba a sentir especial atracción siglos más tarde, era ya para Quintiliano sintomáticamente expresivo. Este pasaje no deja duda: "Con el movimiento expresan [los ojos] entusiasmo o indiferencia, soberbia, fiereza, dulzura o aspereza". Palabras más o palabras menos, repite la idea TH. PrDERIT en su Mimik und Physiognomik, a fines del siglo xix: "Re-

6 Estos avances modernos alcanzan a otras disciplinas ciertamente; pienso en ciertas palabras de Brachart, escritas en 1920, a propósito de los comediantes; era necesario "mostrar" al público que "además de poseer una lengua que les permite recitar más o menos agradablemente el verso o la prosa, tienen también cabeza, ojos, brazos y piernas, de los que hacen uso en los mil incidentes de la vida corriente y que desechan en el teatro". Y no se trataba, según su propia declaración, de hacer pantomima. (Citado por JAN DoAT, L'expression corporelle du comédien, 1944).

7 "Aber ganz so gleichültig den Ausdruck des Gesichtes ist das Auge selbst nicht" (FrITZ Lange, Die Sprache des menschlichen Antlitzes, p. 49). Véase además BüHLER, Teoria de la expresión, p. 165. 
conocemos en la mirada tarda el agotamiento corporal y la pereza espiritual; en la mirada vivaz, excitación; diversos grados de atención tensa en la mirada dulce, participación o pasión; en la mirada errabunda, dispersión; en la insegura, angustia". Era natural que, preocupado originariamente por los recursos de la oratoria, Quintiliano hubiese llevado sus observaciones hasta descubrir la función expresiva de los párpados. Y fue su segundo acierto: “También los párpados y las mejillas contribuyen mucho a la explicación de los ojos"8. Sus apreciaciones ligeras sobre la función expresiva de las cejas prefiguran afirmaciones de la ciencia moderna. Contemporánea resulta su observación de que las cejas "de alguna manera dan realce a los ojos". Lange considera que las cejas, aun cuando pertenecen con más propiedad a la frente, tienen por función esencial "dar expresión al ojo"'. A su valor significativo (a su poder sugestivo, diríamos con propiedad) alude ciertamente Quintiliano cuando recomienda no tenerlas inmóviles, ni moverlas demasiado, así como cuando solicita que dicho movimiento no contradiga lo que decimos: "Porque teniéndolas encogidas se muestra furia; bajas, tristeza; extendidas, alegría. También se bajan o levantan para afirmar o negar".

Este poder expresivo de los ojos ha sido explotado desde un punto de vista "lingüístico" (en el plano de la comunicación entre hablantes) por el teatro. En dos vertientes soluciona el teatro el fenómeno expresivo: la del autor y la del actor representan dos perspectivas del hablante, frente al auditorio, testimonio del oyente.

\section{El gesto EN LA Literatura}

Son interesantes los testimonios de este valor expresivo explotado por la literatura. Quiero apenas destacar algunos textos vinculados con la expresividad encomendada a los ojos. Falta en español un trabajo dedicado a estudiar con criterio lingüístico estos problemas, y no podemos salvar del olvido trabajo alguno que estudie el tema desde el ángulo literario. Hace años publicó Hans Ulrich Espi una hermosa tesis destinada a estudiar el fenómeno en cincuenta años de literatura francesa ${ }^{10}$. Muchos de sus ejemplos me servirán hoy para ilustrar esta nota. Pienso que podríamos reducir a cuatro

8 Véase LANGe, op. cit., pp. 95 ss.

9 "Obwohl die Brauen mehr der Stirn als den Augen zugehoren, tragen sie wesentlich zum Ausdruck des Auges bei...” (ibid., p. 111). Más adelante confirmará Lange a Quintiliano al recordar cómo la falta de cejas quita mucho de su expresión al rostro.

${ }_{10}$ Die Geste als Ausdruckform und ihre Beziehungen zur Rede, Bern, 1949 $(R H e, 33)$. Sólo ha dejado al margen el autor los casos de patología lingüística acogidos por la literatura. Este tipo de estudios ofrece abundante bibliografía para los campos francés, italiano y alemán. 
grandes grupos los distintos movimientos semánticos que pueden realizar los ojos ${ }^{11}$ :

A. I) Alzar los ojos al techo

2) alzarlos al cielo

3) abrirlos

4) inclinarlos

C. 1) desviar los ojos

2) mirar a alguien en los ojos

3) concentrar la mirada en los ojos de alguien

4) menear los ojos

5) mirar oblicuamente
B. 1) bajar los ojos

2) cerrarlos

3) entrecerrarlos

4) guiñar el ojo

D. 1) llevarse las manos a los ojos

2) tapárselos con las manos

3) poner los puños sobre los ojos

4) restregarse los ojos

Estos cuatro apartados pueden ofrecernos por ahora rico material, y un plan provisional de recolección. Elijo solamente algunos ejemplos ilustrativos (me remito, en cada caso, a la precedente clasificación):

(A, 1) Maman secouait la tête de gauche à droite, les yeux au plafond. -Oh! murmura-t-elle. Cette musique!... (Duhamel, Le jardin des bêtes sauvages).

$(\mathrm{A}, 2)$ Elle pâlit et répondit en levant les yeux au ciel: "La volonté de Dieu sera faite" (Balzac, Le lys dans la vallée).

$(A, 3)$ Les yeux lentement s'ouvrirent, la bouche se tordit un peu, prit la forme vide d'un baiser... (Aragon, Aurélien).

$(\mathbf{B}, \mathbf{2})$ Il ferma les yeux, hocha un peu l'épaule. -Bah! fit-il. Ils avaient des ordres... (Vercors, La marche à l'étoile).

$(B, 4)$ Elle échangea un clin d'œil de connivence avec Adrienne qui se retournait vers elle, et disparut dans la foule (Green, Adrienne Mesurat).

$(\mathrm{C}, 2)$ Ils rentrèrent au salon. Alors, Fabienne prit l'homme aux épaules, le regarda dans les yeux: -Salembeau, vous êtes un menteur (Plisnier, Mariages).

$(\mathrm{C}, 4)$ Le juif -vieux, barbe terreuse...- lève le nez au ciel, roule des yeux suppliants, baise les babouches de Sid'Omar, penche la tête, s'agenouille, joint les mains... (Daudet, Lettres de mon moulin).

(D, 1) Mme. Dentin (les mains devant les yeux). -Seigneur! Comment ose-t-il? Comment ose-t-il? (Vildrac, Le pèlerin).

La consideración de estos ejemplos nos regalaría con observaciones interesantes. Por lo pronto, todos los casos confirman la confianza del autor en el valor expresivo de los ojos. Los ojos (el movimiento, la actitud de los ojos) son conllevadores de sentido. Crean

11 Dejamos al margen toda el área relativa al llanto y a las lágrimas, que no aluden estrictamente al problema que nos ocupa. 
a veces la situación idiomática, en algunos casos la refuerzan, en otros son ellos los encargados de la pura predicación. Mientras en el ejemplo de Duhamel son refuerzo inevitable del sentido, cargado evidentemente en las exclamativas, integran el bloque semántico en el caso de Balzac. Como buen ejemplo de teatro, el de Aragon nos coloca ante una pura situación idiomática; dentro del contexto de movimiento (la apertura de los ojos, la disposición de los labios para el beso, son verdaderamente los elementos predicativos, los indicios expresivos), los ojos integran la "organización" del sentido, forman parte de una "sintaxis del gesto". En cambio, Vercors alude a ellos como colaboradores, como apoyo de una situación expresiva: $B a h$ ! es la palabra que se adueña de la expresividad, pero la alusión a los ojos cerrados ofrece una significación acompañante, preparatoria. El carácter dramático del pasaje de Plisnier no sería tan logrado sin la insistente colaboración de la actitud escrutadora confiada a los ojos; esa mirada clavada en Salembeau asegura todo el énfasis al texto, y está para anunciarnos que no se trata de un exabrupto, sino de una acusación meditada, honda, con peso, fruto de una demorada intención; no es ahora cuando "comienza a ser" un mentiroso Salembeau, ahora es el momento oportuno para confirmar una sabiduría paulatina y progresivamente rumoreada. Frente a estos ejemplos, el de Daudet proporciona un contraste digno de ser puesto en relieve: lo expresivo no está remitido a los movimientos del globo ocular, sino que aparece aludido como al desgaire en el epíteto. Signo acompañante (pero signo, con valor lingüístico) tiene evidentemente la actitud exigida por Vercors para Mme. Dentin.

Una evidencia nos imponen estos ejemplos. En la conciencia del hablante está ganada la certeza de que existen actitudes lingüísticas (= expresivas) susceptibles de ser remitidas a los movimientos del globo ocular. Lo que el hablante confía a los gestos no es la comunicación sino la expresividad, es decir, el comentario sentimental, el fondo anímico, las andaderas de la afectividad ${ }^{12}$. Esta conciencia, asegurada en la norma lingüística, es la acogida por la literatura con gozosa frecuencia.

Valle-Inclán fue eximio cultivador del gesto y lo utilizó como vivificador de la situación y de sus personajes; veamos, por ejemplo, el siguiente pasaje de la Sonata de primavera: "El mayordomo me dirigió una mirada oblicua que me recordó al viejo Bandolere que hacía los papeles de traidor en la compañía de Ludovico Straza". A la dirección de la mirada dedicó en 1932 un notable estudio Ph. Lersch, y en él distingue varios campos semánticos; ahí se aclara,

12 Comunica por lo pronto estados emocionales, y en ese sentido resulta evidente que se convierte en lenguaje afectivo (cf. Cuatrecasas, Psicobiologia del lenguaje, p. 199). Para los alcances con que uso aquí "comunicación" y "expresividad", véase mi trabajo El estilo y sus limites, Lima, $195^{8}$. 
por lo demás, que la mirada oblicua suele traducir una especial estructura vital. A esta función semántica corresponde enteramente el ejemplo de Valle-Inclán; la mirada oblicua alcanza en este pasaje de la Sonata una función evocadora de la traición ${ }^{13}$.

Frente al anterior, el pasaje siguiente, de la misma Sonata, ilustra una mirada creadora de situación idiomática, nutrida del mundo interior del hablante: "Me detuve, mirándoles alternativamente; es el juego del ir y venir de los ojos el que "realiza" la situación. Todavía puede alegarse otro caso" ${ }^{14}$; en un pasaje de la Sonata de estio describe Valle-Inclán a una muchacha: "se acercaba con lentitud, dando órdenes a un caballerango que escuchaba con los ojos bajos". Por supuesto, la actitud receptiva reclamada para su protagonista es acá recurso evidentemente "escénico", no extraño en Valle-Inclán; pero confirma asimismo en qué medida el movimiento de los ojos colabora a crear el contexto, así como demuestra, de otro lado, que el movimiento del globo ocular forma parte de un "sistema expresivo": el del rostro.

Universidad de San Marcos

Luis Jaime Cisneros

Instituto de Filología (Lima).

13 Ya Piderit había llamado la atención sobre la fuerza con que esta clase de mirada aludía a la desconfianza.

14 A. ZAMORA Vicente, Las "Sonatas" de Ramón del Valle-Inclán, Buenos Aires, 1951, p. 198 nota, ofrece testimonios de la existencia de un "sistema expresivo" encomendado a los gestos. 